\title{
Mecanic Fish
}

\section{Dariana Narvaez ${ }^{1}$}

${ }^{1}$ Affiliation not available

May 13, 2021

May 3, 2021

\section{Suggested time: 50-60 minutes}

Overview

The students will learn about the bases of water's superficial tension and elasticity of materials by doing trials, and at the end they will apply all the things that they have learned by doing a fish that moves with a mechanism made with recycled materials.

\section{Materials}

* 2 plastic bottles

* Foami

* Scotch tape

* Wooden sticks

* Wooden popsicle sticks

* Silicon

* Scissors

* Rubber bands

* Needle

* Toilet paper

* Cup of water

\section{Multimedia Resources}

Learn about superficial tension $(1: 30-2: 02)$ https://www .youtube.com/watch?v=JZA_NV8I5y0

\section{Lesson}

\section{Part 1: Superficial tension (15 minutes)}

1. Watch and analyze the video about superficial tension and chat about what we learned.

2. Make an experiment to understand more in depth about the tension in water. First they will have to fill a small glass with water and place a needle on top, before doing it ask them if they think it will sink or float (the needle will sink). After this part ask them why they think the needle sunk. 
3. The same experiment will be done but placing a piece of toilet paper and then gently placing the needle on top, after a while the paper will sink and the needle will stay on top of the water floating. After the experiment we will discuss what is happening and ask them why they think that now the pin has not sunk.

\section{Part 2: Body of the fish (10 minutes)}

1. We start by doing the body of the fish, the first thing they must do is to cut the bottle in half, only keeping the parts that have the bottle cap, after that, they will glue them by the parts that don't have the cap and then paste them with tape so they don't have gaps where the water could come in, making the fish float. (attached example in fig. 1)

2. We'll remember the topic of superficial tension by asking the kids why they think the fish will float

\section{Part 3: Making the mechanism! (15-20 minutes)}

1. To make the mechanism that will help the fish to move, they will glue 2 of the long sticks to the ends of the body of the fish, ensuring that they are at the same height leaving a space between them

2. They will take a rubber band and cross it between each of the wooden sticks, in the middle of the rubber band you will place the wooden popsicle stick. This mechanism will serve as a motor to propel the fish. (attached example in fig. 2)

3. We'll make the kids try different rubber band sizes so they can test the different forces the band can make

4. Then, the kids must make an hypothesis of which rubber band will need more turns and which one is the best one to use as the motor (attached example in fig. 2)

5. Then we will explain the concept of elasticity, how all the objects have a different amount depending on their size and material. Kids will make their conclusions with the information they got form testing the rubber bands

\section{Part 4: Let's get creative (10-15 minutes)}

1. The kids will draw the fins and eyes of the fish as they wish

2. For an easier way to glue them, they can leave some extra space in the bottom of each drawing, that is where they can put the glue to paste it

3. The kids will glue the fish fins to the body and decorate with help of glue, this will help their creativity to grow

4. Each one of the kids will present their fish and say their name

Part 5: Try your fish (5-10 minutes)

1. They'll look for a place to try their fish in water and with a big enough place for it to move

2. To try it, they'll need to turn their wooden popsicle stick until they feel enough tension, then they will sink the fish slowly and let go of the stick

3. If there are a lot of kids, they can make a race and play with them (attached example the mecanic fish in fig. 3) 


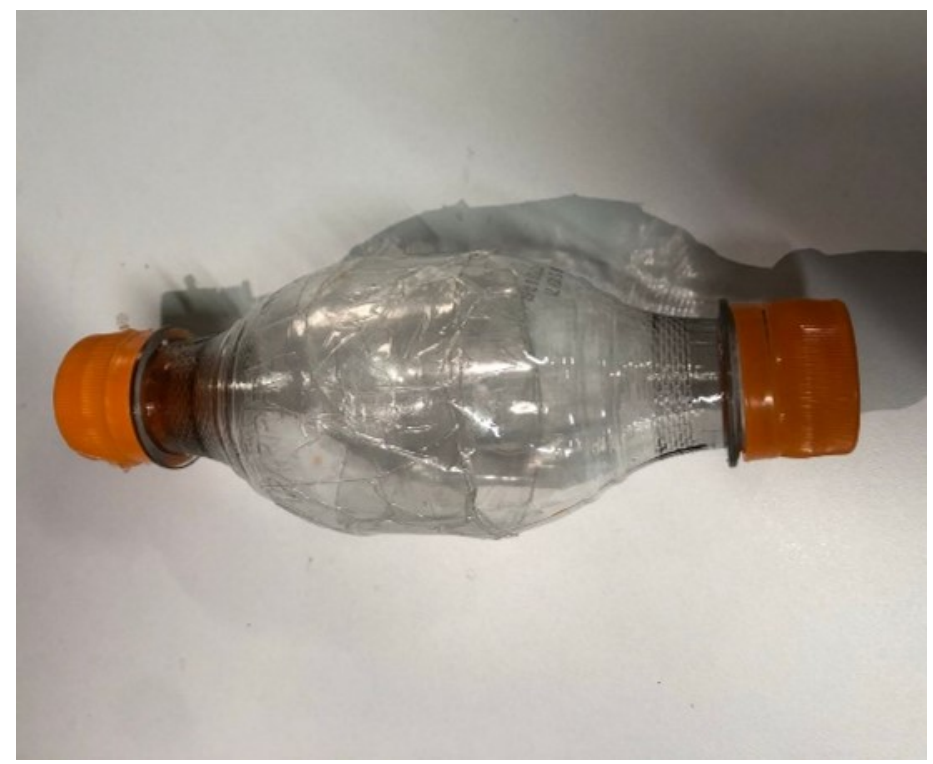

Figure 1: Part. 2

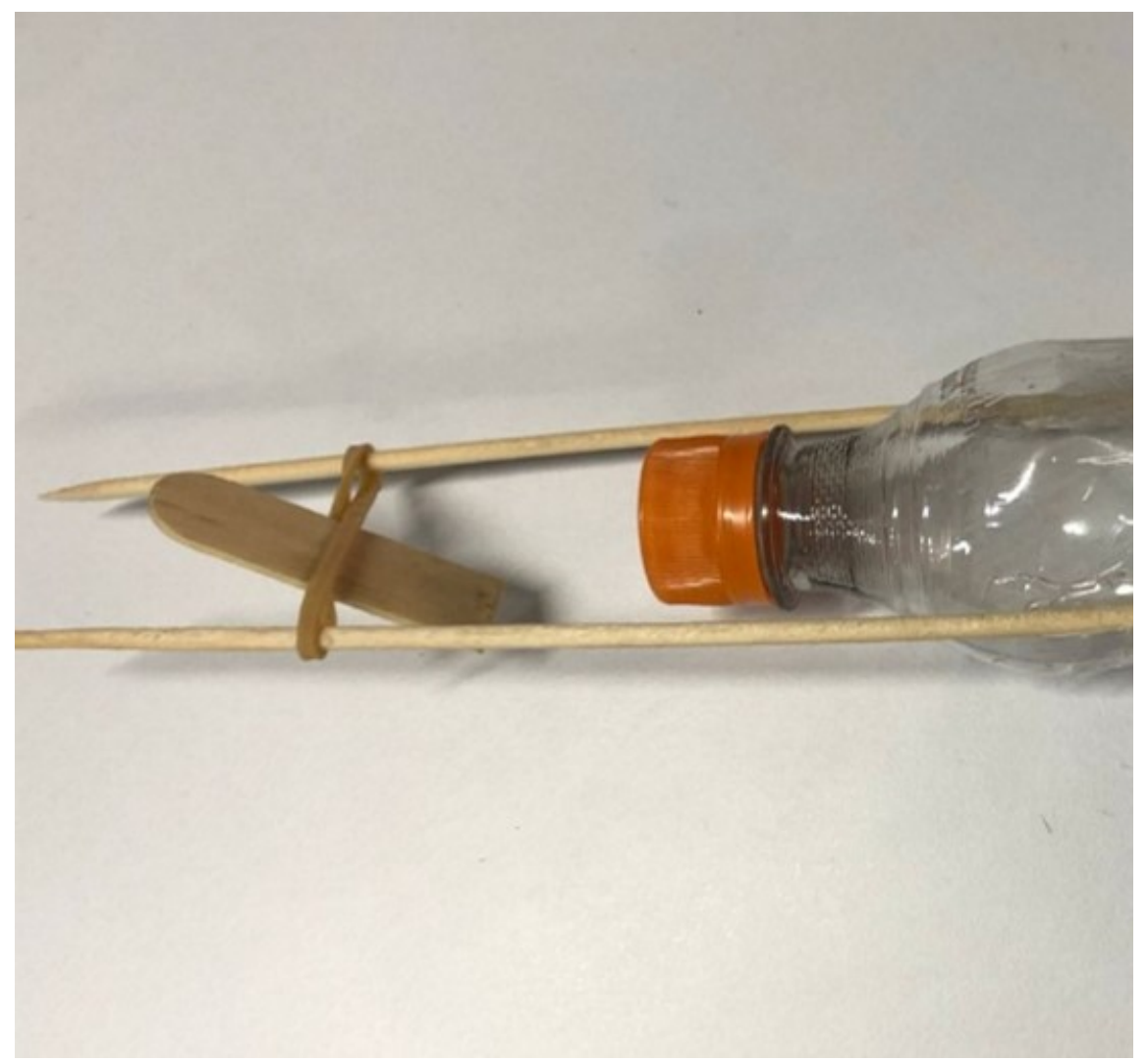




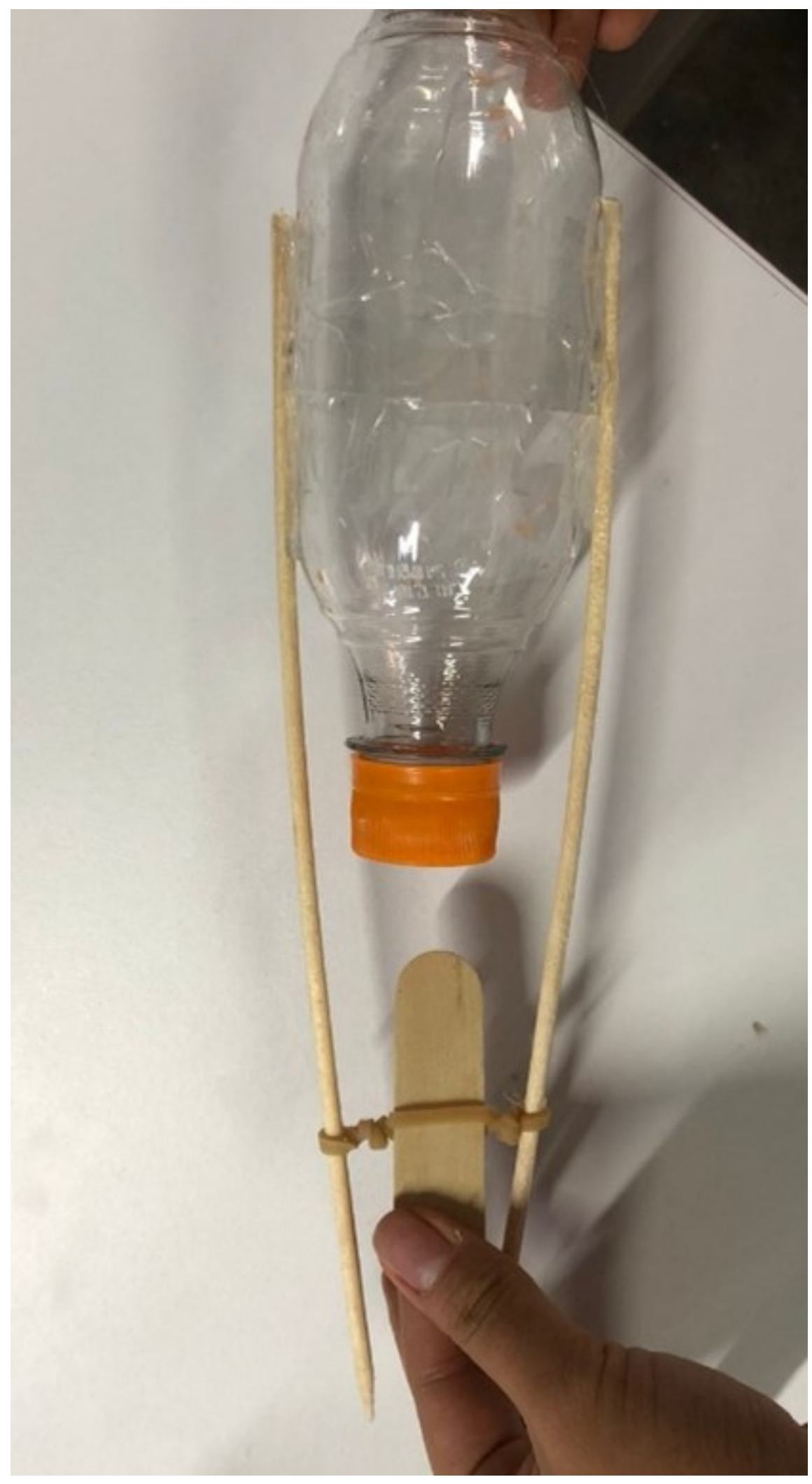

Figure 2: part. 3 


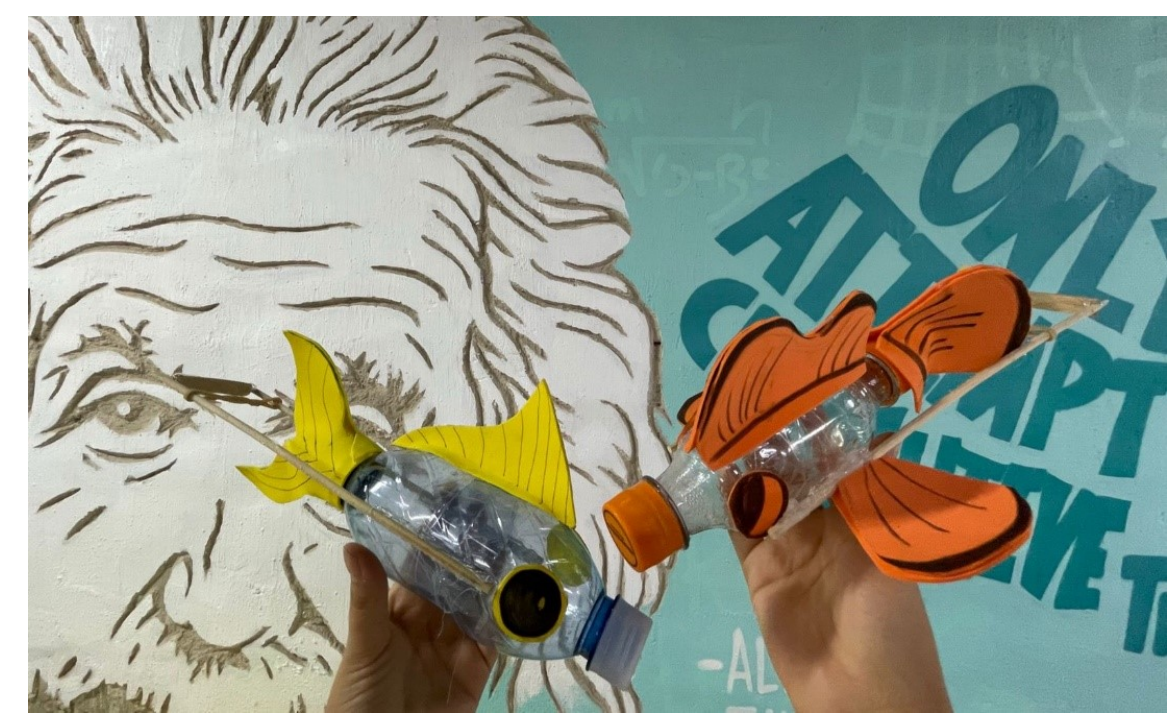

Figure 3: final score 